\title{
Desenvolvimento e testes de células a combustível suportadas pelo anodo com eletrólitos depositados por spin-coating
}

\author{
Development and tests of anode-supported \\ solid oxide fuel cells with electrolyte layer \\ deposited by spin-coating
}

Tabuti, F.N. ${ }^{1,2}$, Fonseca, F.C. ${ }^{1}$, Florio, D.Z. ${ }^{2}$

\author{
${ }^{1}$ IPEN-CNEN/SP - 05508-000, São Paulo, SP. \\ e-mail: ftabuti@gmail.com ; fcfonseca@ipen.br \\ ${ }^{2}$ UFABC - 09090-400, Santo André, SP. \\ e-mail:daniel.florio@ufabc.edu.br
}

\section{RESUMO}

No presente estudo são apresentados os desenvolvimentos de células suportadas pelo anodo usando os materiais convencionais, à base de zircônia estabilizada com ítria (ZEI) e NiO, e técnicas químicas de síntese e de deposição de camadas dos demais componentes: camada funcional, eletrólito e catodo. Os eletrodos foram sintetizados no Instituto de Pesquisas Energéticas e Nucleares (IPEN) por técnicas químicas que garantem homogeneidade de fases e controle de distribuição de tamanho de partículas. Suspensões de ZEI foram desenvolvidas para a deposição por spin-coating (SC) com características que permitam a deposição de camadas do eletrólito com cerca de $10 \mu \mathrm{m}$ de espessura em poucas etapas. Após as deposições, as meias células são co-sinterizadas em temperaturas na faixa de $1300-1500^{\circ} \mathrm{C}$. A deposição de catodos à base de manganita de lantânio dopada com estrôncio (LSM) foi feita pela técnica de wet powder spray de suspensões à base de etanol. As propriedades eletroquímicas das Células a Combustível de Óxidos Sólidos (CCOSs) unitárias foram medidas na faixa de temperatura entre 600 e $800^{\circ} \mathrm{C}$, usando hidrogênio umidificado (3 vol.\% $\mathrm{H}_{2} \mathrm{O}$ ) como combustível e ar como oxidante. Os principais resultados mostram que as camadas do eletrólito são homogêneas e estanques. As células exibiram voltagem de circuito aberto 1 V e bom desempenho em temperaturas intermediárias, confirmando a boa qualidade dos eletrólitos produzidos por SC.

Palavras chaves: suporte anodo, spin coating, deposição, eletrólito.

\begin{abstract}
The present study shows the development of anode-supported solid oxide fuel cells (SOFC) using conventional yttria stabilized zirconia (YSZ) materials and wet chemistry techniques for both the synthesis and deposition of components. Electrodes have been synthesized at IPEN by using wet chemistry techniques, which result in controlled phase composition and homogeneous particle size distribution. Ceramic suspensions of YSZ were developed for their deposition by spin coating to attain $\sim 10 \mu \mathrm{m}$ thick layers with a reduced number of coating steps. Half-cells (anode support/electrolyte) are co-sintered in the $1300-1500^{\circ} \mathrm{C}$ temperature range. Strontium-doped lanthanum manganite cathodes were deposited by wet powder spray of ethanol-based suspensions, followed by a heat treatment at $1200^{\circ} \mathrm{C}$. The electrochemical properties of single SOFCs were measured in the $600-800^{\circ} \mathrm{C}$ temperature range, using humidified hydrogen $\left(3\right.$ vol. \% $\left.\mathrm{H}_{2} \mathrm{O}\right)$ as fuel and air as the oxidant. The main results evidenced that electrolyte layers are dense and homogeneous, as inferred from scanning electron microscopy analysis. Single SOFCs showed open circuit voltage of $\sim 1 \mathrm{~V}$ and good performance at intermediate temperatures, further confirming the gas tightness and good quality of spin coated electrolyte layers.
\end{abstract}

Keywords: anode supported, spin coating, deposition, electrolyte. 


\section{INTRODUÇÃO}

Células a combustível de óxidos sólidos (CCOSs), também conhecidas por pilhas a combustível de óxidos sólidos, têm usado como suporte um eletrodo, geralmente o anodo, que serve de base estrutural para camadas dos demais componentes. Esta configuração visa à redução da contribuição ôhmica do eletrólito por meio da redução da sua espessura. Como a temperatura de operação da célula depende principalmente da condutividade iônica do eletrólito, uma célula construída com camada fina de eletrólito e suportada pelo anodo, tem a vantagem de poder operar a temperaturas intermediárias $\left(600-800^{\circ} \mathrm{C}\right)$ sem perdas significativas de desempenho [1]. Grandes esforços de pesquisa nesta área estão voltados para o desenvolvimento de células a combustível de óxido sólido de alto desempenho em temperaturas intermediárias [2].Estas temperaturas têm como vantagem uma menor exigência sobre os componentes da CCOS, possibilitando mais opções para a seleção de materiais [3]. Esta característica, em última instância, deverá contribuir para a comercialização dessa tecnologia. A CCOS suportada no anodo tem se estabelecido como a configuração estado da arte, sendo adotada por diversos grupos de pesquisa e empresas desenvolvedoras [2]. Neste contexto, o desenvolvimento de técnicas de fabricação de eletrólitos que forneçam boa homogeneidade e alta densidade com custos competitivos é de relevância.

Para as células em configuração planar e suportadas pelo anodo, um importante desafio é a fabricação de eletrólito denso, intransponível aos gases de trabalho, com espessura entre 5 e $15 \mu \mathrm{m}$ [4-6] e com boa aderência ao substrato poroso (anodo) de forma a minimizar as polarizações interfaciais [1]. As técnicas para fabricação da camada fina do eletrólito podem ser dividas em: físicas e químicas. As técnicas físicas (como "pulsed laser deposition" e "sputtering")são adequadas, porém, em geral, tem custo elevado. As técnicas químicas (como "tape casting”, "screen printing”, "dip coating”, "wet powder spraying” e "spin coating”) apresentam a vantagem de serem mais econômicas, mas por outro lado, requerem um controle rigoroso dos diversos parâmetros envolvidos para que sejam eficientes e tenham boa reprodutibilidade [7].

O objetivo deste trabalho é desenvolver a fabricação de CCOSs suportadas pelo anodo com deposição do eletrodo por spin coating (SC). Esta técnica consiste no recobrimento da superfície de um substrato por meio da ação da força centrífuga e é amplamente usada na fabricação de componentes eletrônicos com espessuras, usualmente, entre $10 \mathrm{~nm}$ e $1 \mu \mathrm{m}$. Portanto, a obtenção de eletrólitos com camadas de espessura normalmente usadas em CCOSs suportadas no anodo $(\sim 10 \mu \mathrm{m})$ deve necessariamente envolver uma otimização do processo SC de deposição para que seja realizado em um número reduzido de etapas. Controlando-se os principais parâmetros da deposição, como o tempo e a velocidade de rotação, bem como as propriedades da suspensão usada e os tratamentos térmicos de secagem e de sinterização, foi possível se obter camadas densas e homogêneas de eletrólitos de zircônia estabilizada com ítria. CCOSs unitárias foram fabricadas e o estudo das suas propriedades eletroquímicas nas condições de operação confirmou a boa qualidade dos eletrólitos produzidos.

\section{MATERIAIS E MÉTODOS}

Os compósitos do anodo, com composição final de $45 \%$ em volume de Ni, foram fabricados a partir de pós preparados pela técnica de mistura líquida modificada [8, 9], usando zircônia estabilizada com 8 mol\% de ítria (ZEI, Tosoh), acetato de níquel tetra hidratado (Aldrich) e álcool etílico. A esse compósito foi acrescentado grafite, em diferentes proporções, como formador de poros. Os substratos foram conformados por compactação uniaxial a frio em matriz de $25 \mathrm{~mm}$ de diâmetro. Esses foram tratados termicamente na faixa de $1000^{\circ} \mathrm{C}-1350^{\circ} \mathrm{C}$ para aumento da resistência mecânica e otimização da co-sinterização da meia célula (anodo/eletrólito). As densidades aparentes dos substratos foram determinadas pelo método de Arquimedes.

As suspensões utilizadas na deposição do eletrólito foram preparadas usando uma mistura de terpineol com etil celulose [10-16], e concentração de sólidos entre $20 \%$ e $40 \%$. A suspensão do anodo funcional, a camada interfacial entre o anodo e o eletrólito, foi preparada com concentração de sólidos de 30\% em uma mistura de terpineol e etil celulose. As misturas do eletrólito de ZEI e da camada funcional ZEI-NiO com os aditivos orgânicos foram separadamente homogeneizadas em moinho de bolas por 15h utilizando meios de moagem de zircônia. As deposições por SC foram feitas em um equipamento Laurell WS - 400B - 6NPP com os parâmetros de velocidade de rotação 6000 RPM e tempo de deposição entre 6 e 60s. Após a deposição seguiu-se tratamento térmico a $400^{\circ} \mathrm{C}$ para eliminação dos compostos orgânicos e sinterização a $1450^{\circ} \mathrm{C}$ por 2 horas.

O catodo $\mathrm{La}_{0,65} \mathrm{Sr}_{0,3} \mathrm{MnO}_{3}$ (LSM) foi preparado pelo método dos precursores poliméricos [17, 18] e a camada desse foi depositada sobre o eletrólito por wet powder spraying (WPS) usando suspensões à base de etanol. Um tratamento térmico final a $1200^{\circ} \mathrm{C}$ completou a fabricação das células unitárias. 
Análises de microscopia eletrônica de varredura (MEV, Philips XL-30) da superfície de fratura da seção transversal das células foram realizadas para se avaliar a porosidade, a espessura e a morfologia dos componentes das CCOSs unitárias.

Para as medidas eletroquímicas foram colocadas, sobre a superfície dos eletrodos, telas de platina fixadas com tinta de platina como coletores de corrente. A cura dos contatos de platina foi feita a $800^{\circ} \mathrm{C}$ por 1 hora com taxa de aquecimento e resfriamento de $2^{\circ} \mathrm{C}$ por min. As células foram seladas na extremidade de tubos de alumina utilizando-se cimento refratário comercial (Aremco, USA), que foi curado em temperatura máxima de $260^{\circ} \mathrm{C}$ por $2 \mathrm{~h}$, de acordo com os procedimentos indicados pelo fabricante.

Curvas características de corrente-tensão ( $\mathrm{I}$ - V) foram medidas em um sistema de testes construído no IPEN com controladores de fluxo mássico e controle de temperatura (termopar tipo $\mathrm{K}$, posicionado próximo ao catodo), na faixa de $600^{\circ} \mathrm{C}$ a $800^{\circ} \mathrm{C}$, utilizando hidrogênio umidificado ( 3 vol.\% $\mathrm{H}_{2} \mathrm{O}$ ) como combustível e ar sintético, ambos os gases com fluxo de $50 \mathrm{~mL} \mathrm{~min}^{-1}$. Medidas de impedância foram obtidas em circuito aberto na faixa de frequência de $10 \mathrm{MHz}$ a $0,1 \mathrm{~Hz}$ com amplitude de sinal AC de $10 \mathrm{mV}$. As medidas elétricas foram feitas utilizando um Solartron 1260 FRA acoplado à interface eletroquímica Solartron 1287, conectados por meio de uma interface a um microcomputador com auxílio de um software desenvolvido para controle dos principais parâmetros experimentais e armazenamento de dados.

\section{RESULTADOS E DISCUSSÃO}

Os primeiros testes tiveram o objetivo de obter suportes de anodo ZEI-NiO com a porosidade necessária por meio da adição de grafite $(\mathrm{G})$ como formador de poros. Foram analisados cermets com adição de $\mathrm{G}$ na faixa de 1 a $15 \%$ em massa em amostras de ZEI-NiO + G que foramsinterizadas a $1350^{\circ} \mathrm{C}$ e a $1450^{\circ} \mathrm{C}$. As porosidades foram calculadas por meio do método de Arquimedes, a partir de medidas de massa imersa em água, úmida e seca apresentadas na Tabela 1. Análises termogravimétricas desses compósitos são demonstradas por ARICO et al. [19]. Observa-se que a porosidade aumenta com o aumento da fração de G adicionada, e para ambas as temperaturas de sinterização uma porosidade próxima ao valor desejado ( 30\%) é obtida para as amostras com $10 \%$ em massa de G.

Tabela 1: Valores de massa imersa, úmida e seca, utilizados na determinação das porosidades dos cermets pelo método de Arquimedes.

\begin{tabular}{|c|c|c|c|c|c|c|}
\hline \multirow[b]{2}{*}{ [G] \% MASSA } & \multicolumn{3}{|l|}{$\mathrm{TS}=1350^{\circ} \mathrm{C}$} & \multicolumn{3}{|l|}{$\mathrm{TS}=1450^{\circ} \mathrm{C}$} \\
\hline & MIMERSA (G) & MÚMIDA (G) & MSECA (G) & MIMERSA (G) & MÚMIDA (G) & MSECA (G) \\
\hline 1 & 0,3847 & 0,4672 & 0,4576 & - & - & - \\
\hline 2,5 & 0,4645 & 0,5653 & 0,5521 & - & - & - \\
\hline 5 & 0,3708 & 0,4574 & 0,4398 & 0,3479 & 0,4211 & 0,4150 \\
\hline 10 & 0,3433 & 0,4331 & 0,4073 & 0,3415 & 0,4340 & 0,4038 \\
\hline 15 & - & - & - & 0,3382 & 0,4388 & 0,3999 \\
\hline
\end{tabular}

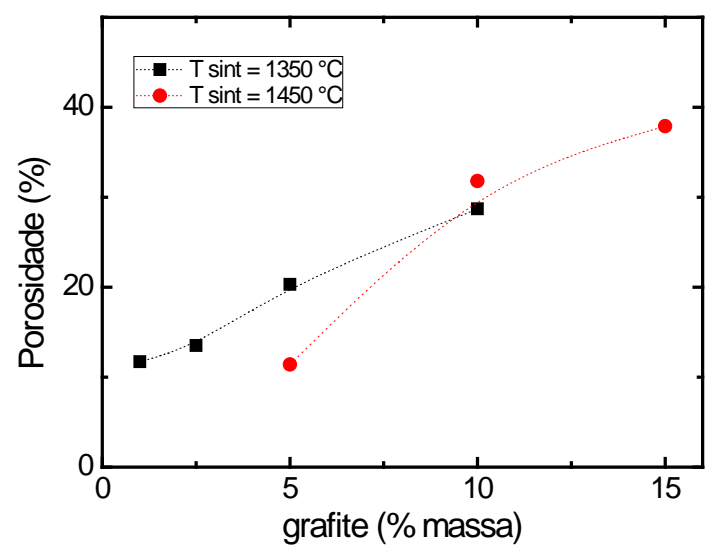

Figura 1: Dependência da porosidade do cermet ZEI-NiO com a concentração de grafite para suportes de anodo sinterizados a $1350^{\circ} \mathrm{C}$ e $1450^{\circ} \mathrm{C}$. 
Tabela 2: Retração diametraldo eletrólito e dos anodos em função da temperatura de tratamento térmico.

\begin{tabular}{l|l|l}
\hline MATERIAL & $\mathbf{T}\left({ }^{\circ} \mathbf{C}\right)$ & RETRAÇÃO DIAMETRAL \% \\
\hline Eletrólito & 1500 & 36 \\
\hline Anodo & 1350 & 15 \\
\hline Anodo & 1200 & 14 \\
\hline Anodo & 1100 & 8,4 \\
\hline Anodo & 1050 & 2,0 \\
\hline
\end{tabular}

Foi realizado um estudo sobre a retração do anodo para determinação da menor temperatura de tratamento térmico necessária para permitir seu manuseio com um mínimo de retração diametral, visando à otimização da co-sinterização da meia célula. A retração diametral dos substratos é apresentada na Tabela 2, na qual se pode observar a retração em porcentagem em função da temperatura de tratamento térmico. Para comparação foi medida a retração de uma pastilha de ZEI (eletrólito) sinterizada a $1500^{\circ} \mathrm{C}$. As diferentes retrações do suporte e do eletrólito podem causar a separação das camadas e é responsável pelo empenamento da meia célula durante a sinterização.

A partir desses resultados pode-se observar que há uma grande diferença nas retrações diametrais do substrato poroso e do eletrólito denso. Outro ponto importante é que com um tratamento térmico a $1200^{\circ} \mathrm{C}$ a retração do anodo já passa a ser significativa (14\%), próxima à retração máxima (15\%) observada em temperaturas próximas às de sinterização do eletrólito $\left(1350^{\circ} \mathrm{C}\right)$. Em função destes resultados, para compatibilizar as retrações das diferentes camadas passou-se a utilizar anodos tratados termicamente a $1100^{\circ} \mathrm{C}$ e $1050^{\circ} \mathrm{C}$.

Nos primeiros testes de deposição por SC, foram obtidas camadas sem homogeneidade e de baixa densidade. Visando o aumento na qualidade destas camadas foram estudados os principais parâmetros envolvidos para a deposição como a concentração de sólidos e a distribuição de tamanhos de partícula da suspensão de ZEI, o tempo de rotação no equipamento de SC, e a temperatura de sinterização. Realizando deposições sistemáticas variando cada um destes parâmetros, e observando as superfícies de fratura das meias células obtidas por MEV, foi possível estabelecer as condições para que se obtenham camadas de ZEI homogêneas, densas e com espessura controlada.

As camadas depositadas sobre suportes de anodo porosos foram as meias células usadas para fabricação de células unitárias por meio da deposição da camada catódica. A Figura 2 mostra a superfície de fratura da seção transversal de uma célula unitária típica. Na micrografia da Fig. 2a é evidenciada a homogeneidade da camada do eletrólito, identificada como a camada densa que separa os dois eletrodos: o suporte do anodo, mais espesso, abaixo e o catodo, acima.Ainda na Fig. 2a é possível verificar a microestrutura deficitária do catodo delaminada pelo processo de fratura da amostra, provavelmente devido à técnica de deposição utilizada, wet powder spray, menos eficiente do que a técnica de SC. Detalhes da microestrutura do eletrólito podem ser observados na Fig. 2b, que mostra a região das interfaces catodo /eletrólito / anodo com maior aumento. A partir dessa imagem,pode-se estimar, por inspeção, a espessura da camada do eletrólito em cerca de $10 \mu \mathrm{m}$, com alta densidade, mas com uma pequena fração de poros fechados com tamanho médio estimado $<1 \mu \mathrm{m}$. Pode-se observar a boa aderência entre as camadas porosas dos eletrodos com o eletrólito, sugerindo a fabricação de uma célula unitária de bom desempenho. 

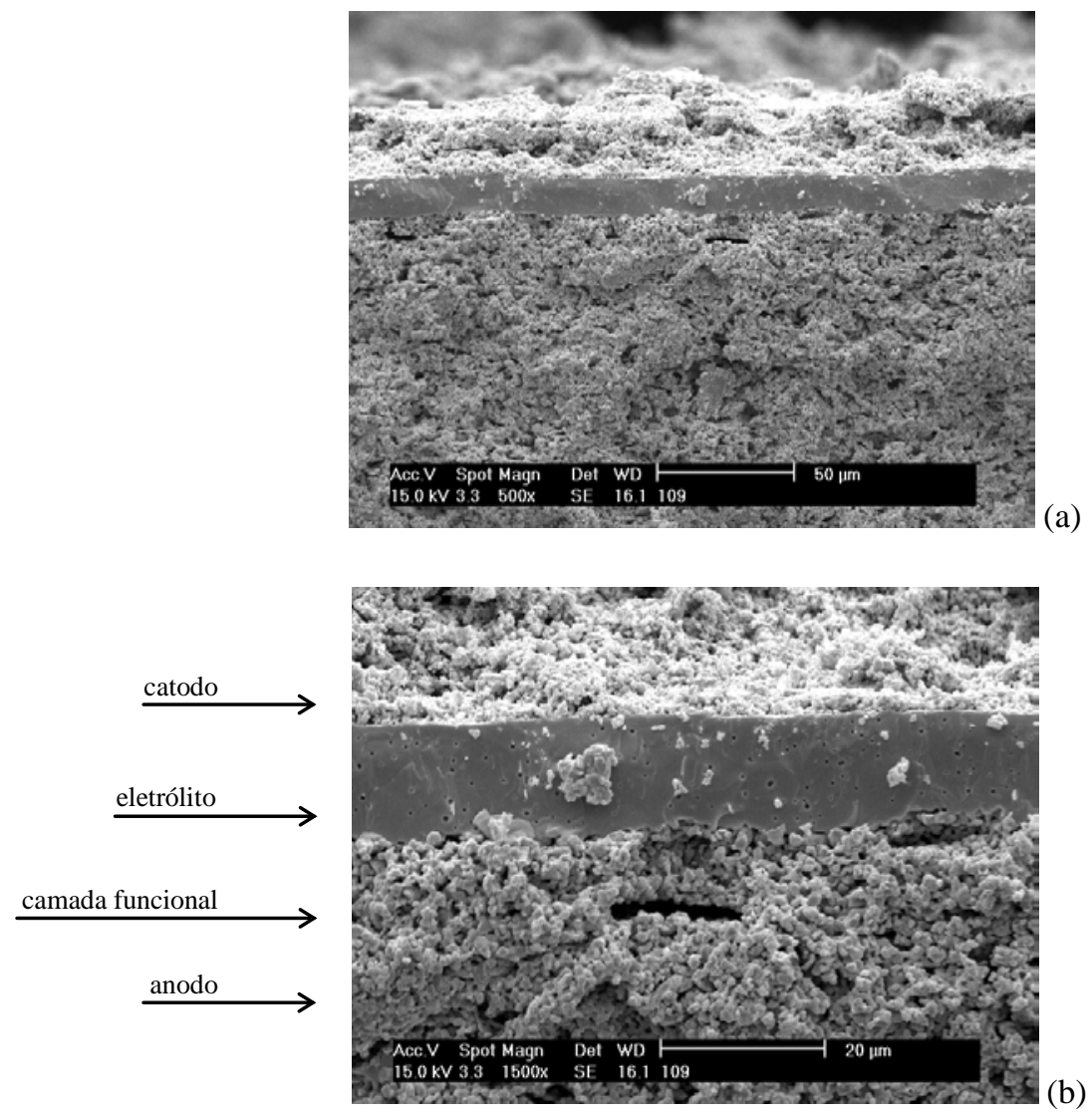

Figura 2: (a) Micrografia de microscopia eletrônica de varredura das superfícies de fratura da seção transversal de uma célula unitária suportada pelo anodo com eletrólito depositado por SC. (b) Detalhe da região do eletrólito com maior aumento.

A boa qualidade da camada do eletrólito foi aferida por meio de medidas eletroquímicas de células unitárias usando hidrogênio como combustível. A Fig. 3 mostra os resultados de curvas de polarização (Fig. 3a) e de impedância eletroquímica em circuito aberto (Fig. 3b) de uma célula unitária produzida nas mesmas condições da célula mostrada na Fig. 2. O resultado mais significativo é a obtenção de tensões de circuito aberto acima de $1 \mathrm{~V}$, próximas aos valores teóricos esperados para as reações eletroquímicas de uma CCOS operando com hidrogênio. Este valor é a indicação eletroquímica de que a camada do eletrólito é estanque aos gases e que a reações de redução do $\mathrm{O}_{2}$ e de oxidação do $\mathrm{H}_{2}$ ocorrem sem perdas por mistura através da célula. Como esperado, o aumento da temperatura de operação melhora o desempenho da CCOS. Em $800{ }^{\circ} \mathrm{C}$ a célula mostra uma curva de polarização com características similares às exibidas usualmente por CCOSs com densidade de potência máxima de $\sim 200 \mathrm{~mW} \mathrm{~cm}^{-2}$. Este valor sugere que existem perdas por polarização que impedem as células unitárias de atingir $\sim 1 \mathrm{~W} \mathrm{~cm}^{-2}$ de potência máxima, o valor estado da arte para CCOS suportadas no anodo [1]. Para melhor investigar estas perdas foram realizadas medidas de impedância, mostradas na Fig. 3b. Os diagramas de impedância mostram que a resistência de alta frequência, associada essencialmente ao eletrólito, diminui com o aumento da temperatura, e são relativamente baixas $\left(\sim 0.5 \Omega \mathrm{cm}^{-2}\right.$ a $800{ }^{\circ} \mathrm{C}$ ). Por outro lado, mesmo exibindo uma diminuição com o aumento da temperatura, a polarização total da célula é de $\sim 3 \Omega \mathrm{cm}^{-2}$ a $800{ }^{\circ} \mathrm{C}$, sugerindo que as maiores polarizações são devidas a contribuições eletródicas. Baseado nos resultados experimentais é provável que as polarizações mais significativas sejam associadas ao catodo. Neste sentido, dois aspectos devem ser considerados:(i) é bem estabelecido que compostos LSM não são adequados para operação em temperaturas intermediárias $\left(\leq 800{ }^{\circ} \mathrm{C}\right)$ e (ii) a camada catódica depositada por WPS não apresentou microestrutura otimizada para células de alto desempenho (Fig. 2a). 


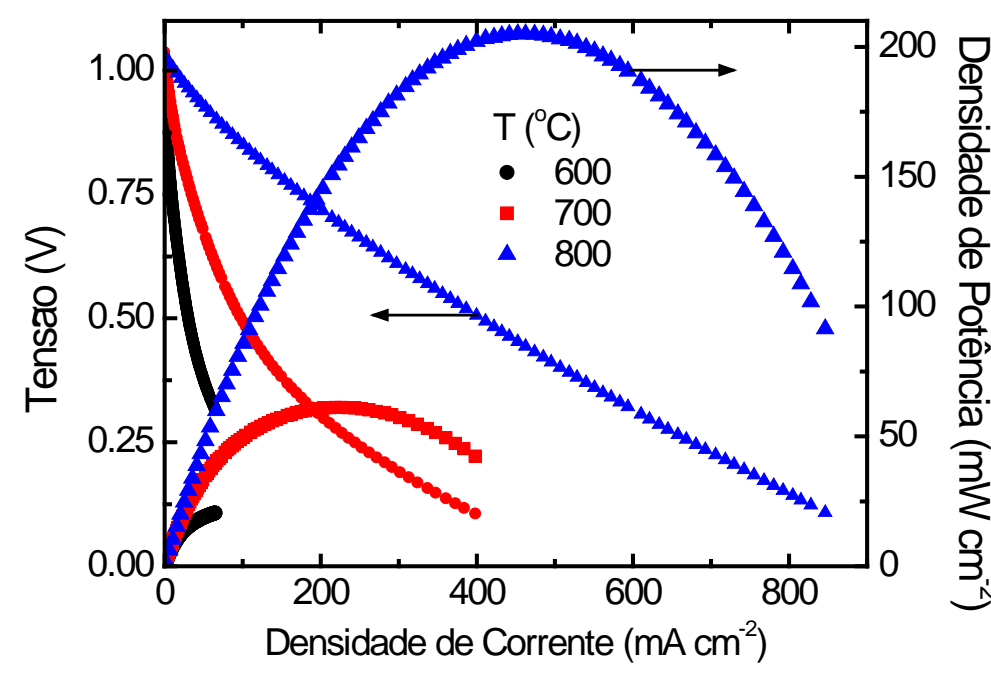

(a)

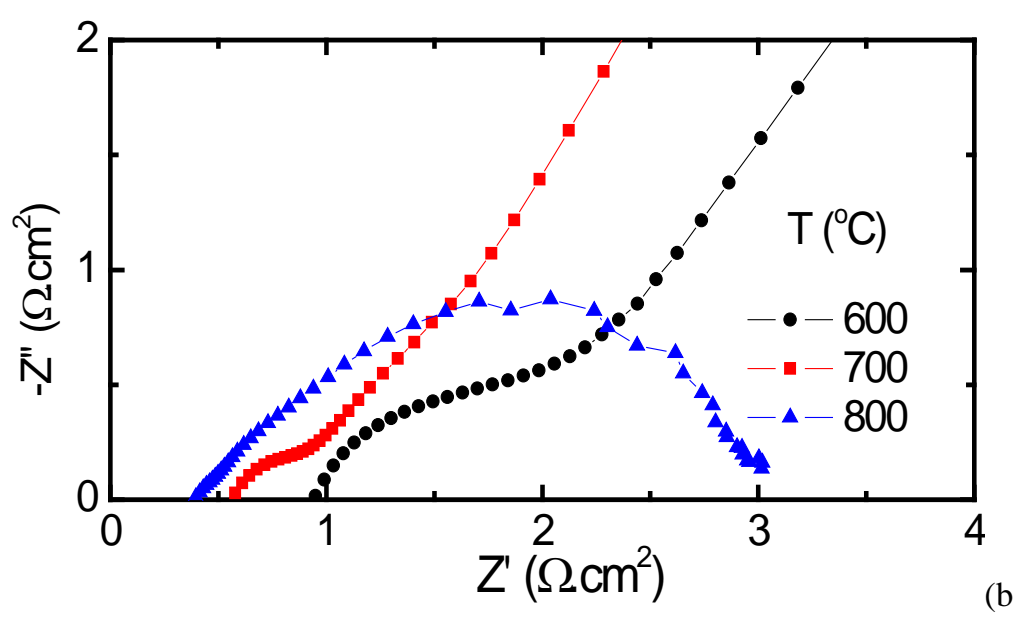

(b)

Figura 3: (a) Curvas de polarização (eixo y-esquerda) e de densidade de potência (eixo y-direita). (b) Diagrama de impedância em circuito aberto.

\section{CONCLUSÕES}

Baseado nos resultados combinados de microscopia eletrônica de varredura e medidas eletroquímicas é provável que as perdas por polarização mais significativas durante os testes das células unitárias estejam associadas ao catodo. Mesmo levando-se em consideração que a espessura dessa camada é aparentemente menor do que a camada anôdica, pois é conhecido o fato de que o LSM não é adequado para operação em temperaturas intermediárias $\left(\leq 800{ }^{\circ} \mathrm{C}\right)$. Como pode ser observado (Fig. 2) a microestrutura da camada catódica não é otimizada devido a técnica de deposição utilizada (wet powder spray).

A otimização dos parâmetros envolvidos na deposição por SC demonstrou que esta técnica é efetiva para a fabricação de camadas finas, homogênease densas de eletrólitos à base de zircônia. A obtenção de células a combustível de óxido sólido suportadas pelo anodo com eletrólitos estanques foi confirmada pelas propriedades microestruturais e eletroquímicas de células unitárias operando com hidrogênio em temperaturas intermediárias.

\section{AGRADECIMENTOS}

Os autores agradecem ao CNPq, FINEP e CNEN pelo financiamento recebido e bolsas.

\section{BIBLIOGRAFIA}

[1] BASU, R.N., SHARMA, A., DUTTA, A., et al. , "Processing of high-performance anode-supported planar solid oxide fuel cell”, International Journal of Hydrogen Energy , v.33, pp. 5748-5754, 2008. 
[2] FLORIO, D.Z.,VARELA, J.A., FONSECA, F.C., et al., "Direcionamentos da tecnologia industrial de células a combustível de óxidos sólidos”, Química Nova v.30, n.5., pp. 1339-1346, 2007.

[3] FLORIO, D.Z., FONSECA, F.C., MUCCILLO, E.N.S., et al., Materiais cerâmicos para células a combustível”, Cerâmica, v.50, n. 316, pp. 275-290, out./dez. 2004.

[4] HAN, M-F., YIN, H-Y., MIAO, W-T., et al., Fabrication and properties of anode-supported solid oxide fuel cell Solid State Ionics”, v.179, n. 27-32, pp. 1545-1548, 2008.

[5] LENG, Y.J.,CHAN, S.H.,KHOR, K.A., et al., "Performance evaluation of anode-supported solid oxide fuel cells with thin film ysz electrolyte”, International Journal of Hydrogen Energy , v.29, n.10, pp. 10251033, August 2004.

[6] XIA, C., CHEN, F., LIU, M., "Reduced-temperature solid oxide fuel cells fabricated by screen printing" Electrochemical and Solid-State Letters, v.4, n. 5, pp. A52-A54, 2001.

[7] WILL, J.,MITTERDORFER, A.,KLEINLOGEL, C., et al., "Fabrication of thin electrolytes for secondgeneration solid oxide fuel cells”, Solid State Ionics, v.131, pp. 79-96, 2000.

[8] FLORIO, D.Z., ESPOSITO V., FONSECA, F.C., et al., "Electrical properties of YSZ/NiO composites prepared by a liquid mixture technique”, Journal of European Ceramic Society, v.25., pp. 2637-2641, 2005.

[9] FONSECA, F.C., FLORIO, D.Z., ESPOSITO, V., et al., "Mixed ionic-electronic YSZ/Ni composite for SOFC anodes with high electrical conductivity", Journal of the Electrochemical Society v.153, n.2, pp. A354-A360, 2006.

[10] CHEN, K., LÜ, Z., AI, N., et al., 'Development of yttria-stabilized zirconia thin films via slurry spin coating for intermediate-to-low temperature solid oxide fuel cells', Journal Power Sources, v.160, n.1, pp. 436-438, 2006.

[11] CHEN, K., LÜ, Z., AI, N., et al., 'Fabrication and performance of anode-supported ysz films by slurry spin coating’, Solid State Ionics, v.177, n.39, pp. 3455-3460, 2007.

[12] WANG, J.,LÜ, Z., HUANG, X., et al., 'YSZ films fabricated by a spin smoothing technique and its application in solid oxide fuel cell Journal of Power Sources', v.163, n.2, pp. 957-959, 2007.

[13] WANG, J., LÜ, Z., HUANGA, X., et al., 'YSZ films fabricated by a spin smoothing technique and its application in solid oxide fuel cell Journal of Power Sources' Journal Power Sources, v.163, n.2, pp. 957959, 2007.

[14] DING, X., GU, J., GAO, D., et al., "Preparation of supported srceo3-based membrane by spin coating method”, Journal Power Sources, v.195, n.13, pp. 4252-4254, 2010.

[15] JASINSKI, P., MOLINA, S., GAZDAB, M., et al., Journal Power Sources (2009) 11538.

[16] HUI, R., WANG, Z., YICK, S., et al., "Fabrication of ceramic films for solid oxide fuel cells via slurry spin coating technique”, Journal Power Sources, v.172, n.2, pp. 840-844, 2007.

[17] RUDER, A., BUCHKREMER, H.P., JANSEN, H., et al., Wet powder spraying—a process for the production of coatings “, Surface and Coatings Technology, v.53, n.1, pp. 71-74, 1992.

[18] MUCCILLO, R., MUCCILLO, E.N.S., FONSECA, F C., et al., "Development and testing of anodesupported solid oxide fuel cells with slurry-coated electrolyte and cathode”, Journal Power Sources, v.156, n.2, pp. 455-460, 2006.

[19] ARICO, E., TABUTI, F., FONSECA, F.C., et al., "Carbothermal reduction of the ysz-nio solid oxide fuel cell anode precursor by carbon-based materials”, Journal of Thermal Analysis and Calorimetry, v.97, n.1, pp. 157-161, 2009. 